\title{
A new pyranoxanthone from the stem bark of Calophyllum buxifolium
}

\begin{abstract}
A new pyranoxanthone, buxixanthone (1), was isolated from the stem bark of Calophyllum buxifolium along with three other chemical constituents, ananixanthone (2), pyranojacareubin (3), and macluraxanthone (4). The structures of these compounds were confirmed through spectroscopic analysis, which included 1D and 2D NMR, GC/MS, and IR experiments.
\end{abstract}

Keyword: Calophyllum buxifolium; Pyranoxanthone; Buxixanthone 